European Journal of

Cultural Studies

\title{
The mediation of childbirth: 'Joyful' birthing and strategies of silencing on a Facebook discussion group
}

\begin{tabular}{|r|l|}
\hline Journal: & European Journal of Cultural Studies \\
\hline Manuscript ID & ECS-17-0062.R1 \\
\hline Manuscript Type: & Original Manuscript \\
\hline Keywords: & childbirth, mothering, mediation, users, digital \\
\hline Abstract: & $\begin{array}{l}\text { The mediation of parenting has recently occupied sociologists, media, } \\
\text { communication and cultural studies scholars alike. This paper locates itself } \\
\text { within this developing strand of research, as it explores discourses of } \\
\text { intensive motherhood on a Facebook discussion group providing support } \\
\text { and advice for a specific approach to and philosophy of childbirth. } \\
\text { Presenting findings from an analysis of main posts and comments made on } \\
\text { them, I tease out the brighter and darker sides of the performance of } \\
\text { motherhood in anticipation of birth, on social media, reading these against } \\
\text { discussions about the self-managing, intensive mother responsible for } \\
\text { making the very best decisions for her child. }\end{array}$ \\
\hline
\end{tabular}




\section{FACEBOOK BIRTH INTENSIVE}

\section{The mediation of childbirth: 'Joyful' birthing and strategies of silencing on a Facebook discussion group}

This paper reports from a small section of the larger body of material analysed in the project Birth Stories, funded by the British Academy to run from 2016 till 2018, developing an account of the mediation of childbirth in the UK and USA (Author Removed, forthcoming 2018). The paper presents a thematic analysis, following Riessman (2008), of themes arising from posts in a public Facebook group on hypnobirthing which is said to include a wide variety of practices before, at and shortly after birth, including relaxation, hypnosis, self-hypnosis, and most importantly a steadfast rejection of medical intervention or even medical settings, to have a "better" birth. It develops its framework in three steps. First, I place this project within the theorization of mediation within the field of media and communication studies, outlining the main arguments that have been proposed over the last decades on developing relationships between the media and social, cultural and political institutions, embedding and weaving the media into these. My second step develops the conceptual picture of the maternal as it is invoked in this project on the mediation of childbirth. This strand draws on the theorization of intensive motherhood developed in the late $20^{\text {th }}$ century, which brings to the fore essential concepts such as the maternal ideal, good and bad mothering, and performances of motherhood and mothering in neo-liberal societies. This helps to unpack the ways in which the intensive motherhood discourse privileges an individualized, idealized maternal subjectivity. The third strand 


\section{INTERPRETATION INTERNET AGE}

presents an understanding of the relationship between media, story and narrative. This references developments on narrative, illness and social media within e-health studies which have theorized the power of narratives to both resource people to make sense of their own experiences, and, through constant reproduction, do important identity work, producing themselves and by extension others as subjects of differential value.

\section{Mothers on social media}

Perdersen's (2013) account of mothering on the parenting forum Mumsnet discusses how images of good and bad mothers are both constructed and critiqued on the forum. She converges discourses of intensive motherhood and mothering ideologies to analyse mothers' discussions and points outs that mothers re-work and resist the good mother ideal while being conscious of how all these ideals are increasingly mediated (see also Cheresheva's 2015 study on online narratives of infant feeding in Hungary and Bulgaria; Pedersen and Lupton, 2016 and Gray, 2013). Chen (2013) offers a critique of mothers blogging, from a techno-feminist perspective which is reminiscent of the wider public derision around women's forums and women's online talk that can be traced back to the historical derision towards romance novels for example (Hobson, 1982; Brundson, 1981; Radway, 1984). Offering a critique of the semantic connotations of the term 'mummy blogging' Chen counters the terminology as reducing the authors of these blogs to nurterers and carers alone. As I have argued elsewhere (author removed) the mommy terminology paternistically endows these social media practices with qualities that move them from the centre of 


\section{INTERPRETATION INTERNET AGE}

investigative priorities to the periphery by using the word mommy (instead of mother for example) and that this then works as a convenient, ready-to-employ device of light-hearted dismissal of these texts as anything to be seriously taken or analysed. There is thus, a broader debate to be had about the words we use to refer to women's/mothers' textual practices on social media. This is reflected to an extent in the title of Brady \& Guerin's (2010) work on online parenting discussions where they say these sites are 'not all romantic, all happy, coochy coo'. Rogers' (2015) terminology of “maternal essayists” resolves part of this dilemma by drawing attention to the syntactic and semantic textures of mothers' writing on the web - their narrative techniques, artistic self-expression and negotiations of agency. Lopez (2009) positions these writings as a radical act, Johnson (2014) as intimate mothering publics, Perdersen and Smithson (2013) as an articulation of new forms of femininity and Morrison (2011), as the grounds for an 'intimate public' to become visible. Other notable contributions to the area include Dahlen and Homer's (2011) work on how these texts feed into broader societal discourses around parenting, Pettigrew et al (2015) on their roles in the maintenance of social ties and managing of stress related with parenting, Chen's findings recently (2015; also Chan, 2008) on engagement, information providing and recreational aspects of the process, the Cyberparents project on the convergence of online and offline support, as well as their simultaneously emancipatory and restrictive potentials (O’Connor and Madge, 2010; 2006), Thomas and Lupton's critique of pregnancy apps as artefacts enacting bodies as sites of risk and pleasure, 


\section{INTERPRETATION INTERNET AGE}

amongst others. What is clearly visible across these different pieces of work is a critical engagement with mothers' online writing which often reveals more than the usually expected accounts of conviviality and camaraderie. These are complex spaces, where identities, emotions and ideologies intersect to produce performances of many aspects of maternal identity - making them function as lenses into the norms, conditions and pressures on contemporary parenting.

\section{Mediation, the maternal and narratives}

The research which has developed on childbirth, excluding purely medical or technical literature, has been widely interdisciplinary, spanning fields like sociology, medical humanities, anthropology, feminist geography, art history, history of medicine and visual culture studies. Within this diverse arena, generations of research have accumulated (see Tyler and Baraitser, 2009) and it is only lately that attention has been devoted more specifically to the media and its relationship with birth as a mediated process. Of particular relevance here is work on YouTube and the mediated subjectivities of birth (c.f. Longhurst, 2009; Mack, 2016), Tyler and Baraitser's work on the visual cultures of birth (2013), Tyler's broader history of work on pregnant bodies and maternity (Tyler, 2000, 2001, 2009), De Benedictis's work on the reception of the television show One Born Every Minute (2017), an ongoing network in the UK on Televising Childbirth and recent work on birth and television (c.f. Sears and Godderis, 2011, Luce et al, 2015; Horeck, 2016) deserve particular mention in this context. Birthing and motherhood in Western modernity has 


\section{INTERPRETATION INTERNET AGE}

witnessed, like possibly all other spheres of life, a rapid and progressive entrance of media and communication technologies into its realm, shaping the ways in which mothers communicate, find information and connect with each other, the ways in which institutions address women and their families, the ways in which healthcare professionals engage with their patients, and indeed the ways in which mediated visual cultures around us, from YouTube to Vlogs to Microblogs mediated bodies and maternity. Whether one looks at these processes as interruptions, or as developments in the solely positive sense of the term, arguably, like countless other societal processes, birthing itself, in the way it is represented, discussed, experienced and even managed, is increasingly mediated. Following Roger Silverstone (1999), John Thompson (1995), and Nick Couldry (2004), in this paper, I understand mediation to encompass the whole host of communicative practices with media technologies, distinct from either media effects, or simply audience interpretations of texts, or even a general comment on media saturation in society. The mediation of childbirth would, necessarily, be a multi-pronged process - above and beyond isolated instances of textual representations, snippets of online conversations or focused and specific moments of audience reception of texts. Although this paper reflects on one discrete moment from these instances, and instances like these remain the units of empirical analysis in the field, the process of mediation encompasses all of these and beyond - involving texts, institutions, individuals and societies in multiple lines of interaction. Birthing mothers, other mothers, partners, midwives, other health care organisations and professionals, 


\section{INTERPRETATION INTERNET AGE}

relatives and friends, as "social actors become progressively dependent on the supply of public meanings and accounts of the world in attempting to make sense of their own" (Silverstone, 2002, p 762). Silverstone (2002) goes on to outline something that becomes for me a key device with which to make sense of how certain stories might be highlighted over others, certain voices silenced, as discourses and narratives of birthing develop in society -

As such, mediation has significant consequences for the way in which the world appears in and to everyday life, and as such this mediated appearance in turn provides a framework for the definition and conduct of our relationships to the other. (p 762)

As the logical next step of my attempt to bring together a framework spanning widely different areas, I carry these 'frameworks of reference', the 'management of visibility', the 'struggle for recognition' and the selective highlighting/silencing of voices into an engagement with feminist theorizations of the maternal, which too, engages with precisely these ideas of identity work, subjectivities and selective silencings. Attention to maternal work as a coherent set of tasks and functions (Ruddick 1989) a few decades ago began to recognize the unconscious intersubjective dynamics involved in motherhood (Hollway 2001). Critical analysis of infant development (including the hyper-mediated nature of infant imagery) has shown to erase a discussion of maternal development except in relation to the well-being of the fetus and infant (Parker 2009). Parker (2009) coined 


\section{INTERPRETATION INTERNET AGE}

term "maternal ideal" where the emotional inability to ever separate from her baby is an ideal held up, which can be traced through conceptualizations of 'good' mothering and 'bad' mothering, relating to the 'deviancy' debates on good and bad parenting as strongly classed discourses of neo-liberalism (Jensen, 2012). One of the key aspects of the mediation of birthing has been, they argue, how childbirth TV has rendered birth affectively visible yet silenced the woman as caught between institutions, with birth as something to be feared and as highly medicalised. Yet, as de Benedictis's (2017) account of the reception of One Born Every Minute reveals, the reverse - the enjoyable, peaceful, natural birth prepared for in high-cost classes, often a resource for the middle-class mother - has become the ideal and idealized birth, tying very closely into discussions of good and bad mothering by invoking images of good and bad birthing. What makes childbirth particularly fascinating as a site of analysis in exploring its mediation on social media platforms, is the juxtaposition of two discourses - the emancipatory, feminist revival of women asserting themselves against the white-coated, often male, medical community, harking back to the introduction of the natural birthing movement in the UK (Kitzinger, 2012), for example, on the one hand, and on the other, the neo-liberal, self-regulating, self-managing, highly individualized discourse of ideal births and ideal birthing modes which sit within the intensive motherhood discourse. Rather than seeing them as competing discourses, it is more productive to consider natural birth - and by extension, women's talk on birthing on social media, as a coin of which these represent two sides. I turn attention now to the term 


\section{INTERPRETATION INTERNET AGE}

intensive mothering which was coined in 1996 by Sharon Hays to represent a group of widely held beliefs about the necessity of investing vast amounts of emotional labour and energy into raising their children, which went above and beyond the perhaps obvious strength of emotions that would usually exist between mother and child (Arendell, 2000; Miller, 2007). Historically this has been a highly raced and classed discourse, driven strongly by white, middle-class values, which has later been critiqued in analyses of mothering in young, low income communities (e.g. Romagnoli and Wall, 2012) and in black communities (Elliott et al, 2015; McCormack, 2005). As several scholars point out (Nadesan, 2002; Harris, 1998; Bruer, 1999) this discourse has been mobilized at various private and public institutional levels placing a strong imperative in the hands of parents, especially mothers to invest more than usual amounts of physical and emotional energy into specific activities and practices with children without which they might themselves be putting their children's interests last, or undertaking enormous risks. As is evident from the scholarship (Lupton, 1999; Petersen, 1997), this positions two kinds of risk. The first positions a heightened sense of risk in all aspects of child-rearing simply by establishing the one, right, good way of parenting/mothering.. The second aspect of risk (see also Lupton, 1999 for an excellent discussion) here involves groups who are outside of what is a predominantly middle-class discourse (See Wall, 2010 and Fox, 2009), and therefore at risk (see Lee et al, 2010; also Furedi, 2008). This includes young mothers who are often the subject of reality television shows (see Macvarish, 2010), mothers from lower income 


\section{INTERPRETATION INTERNET AGE}

communities, or from non-White backgrounds, where many of the choices and practices encouraged and held in high regard within the intensive mothering discourse may not be available or accessible to certain groups. Chae (2015) in an analysis of Korean mothers reveals the uptake of the intensive mothering discourse primarily within middle-class women who also drew from celebrity mothers, in terms of inspiration. It is crucial to note here though, that findings from mothering, return to work and childcare practices in Chile (Murray, 2015), reveal lower-income groups embracing the intensive mothering ideology more so than middle-class mothers. As Murray notes, this is a "contrast with the assumption of a dominant parenting ideology of the privileged middle class (Hays, 1996)_ both local and global_operating as the starting point for evaluating the rest." (p 1173). Butler's engaging (2010) analyses of mothering practices and ideology in British Columbia reveals how state regulatory literature subtly works in intensive mothering and frames parenting practices in general as deeply individual responsibilities within their 'Investing in Children' framework, marking a clear shift from a previous approach to parenting which followed a 'family responsibility' framework. The critical role this discourse plays, as its seeps out into the everyday division of labour at home, childcare responsibilities and sundry household roles, is notable, as Coltrane (2010) points out. The logic they find is in a focused rehearsing and reinforcing of traditional gender roles, whereby these sacrifices (presented as worthy) make the male of the household capable of becoming ultraproductive. The stay at home mother, who speaks often of her 'choices' is then, a neo- 


\section{INTERPRETATION INTERNET AGE}

liberal subject, as evident from their analysis (see also McRobbie, 2013; Gill \& Orgad, 2016, writing on 'confidence cultures' in girls; and Littler, 2013, p 227, writing about the “conservative fantasy of autonomous, individualizing retreatism” of 'yummy mummies').

I began this framework by drawing attention to mediated frameworks of reference which involve the power to silence and highlight voices over a struggle for visibility and recognition, and traced the enacting of these struggles through the good and bad mothering discourse evident in critical analyses of the maternal in contemporary neo-liberal societies. The mechanics of this can be understood by observing the use of narrative and the power of stories, as we see traces of these discourse unfold on social media. Bamberg, Schiffrin, and de Fina (2007) develop theorisations of how this work outlined above is done by the use of narrative to present, produce, maintain and reproduce oneself and one's own identity by creating a coherent story to tell. Illness narratives (Frank, 1995) are particularly relevant for this paper - where it is increasingly evident, in many areas of e-health, that there is an emphasis on 'coherent narratives with a positive outcome, hence favoring restitution and progressive narratives' (Page, 2012, p 50). Narratives for analysis are almost mainly, long, detailed, autobiographical ones - like a single person's story, or one single interview transcript. In an interesting essay, Georgakapoulou (2006) questions this, and reminds us of the importance to pay equal attention to what she calls "small stories". These, in her words are -

"a gamut of under-represented narrative activities, such as tellings of ongoing events, future or hypothetical events, shared (known) events, 


\section{INTERPRETATION INTERNET AGE}

but also allusions to tellings, deferrals of tellings, and refusals to tell. These tellings are typically small when compared to the pages and pages of transcript of interview narratives. On a metaphorical level though, small stories is somewhat of an antidote formulation to a longstanding tradition of big stories .. the term locates a level and even an aesthetic for the identification and analysis of narrative: the smallness of talk, where fleeting moments of narrative orientation to the world (Hymes, 1996) can be easily missed out on" (p 146)

\footnotetext{
Riessman (2008) speaks of how "talk among speakers is interactively (dialogically) produced and performed as narrative” (p 105). Riesmann's account of the nature and purposes of storytelling is particularly relevant for this project, where she says "storytelling is a relational activity that encourages others to listen, to share and to empathize. It is a collaborative practice and assumes that tellers and listeners/questioners interact in particular cultural milieus and historical contexts... We ask why was the story told that way?" (Riesmann, 2013, p 170). These functions of storytelling with mediated technologies, for the precise purpose of producing and reproducing oneself and others, within mediated frameworks of reference comes close to the idea of media-oriented practices (Couldry, 2004) as a device with which to make sense of women's frameworks, references and practices with the media and how these lay conceptual repertoires inform their engagement with their own bodies, their own birthing experiences, others' experiences and childbirth and early maternity in general. These encompass the wide variety of their
} 


\section{INTERPRETATION INTERNET AGE}

mediated communication habits, and these locate themselves within everyday lives and contribute to the mediation of childbirth within everyday life.

\section{Methodology}

The Facebook group in question in this paper is a very active group with over 7000 members, including many birth-support practitioners, such as doulas and hypnobirthing teachers, deriving most of its membership from mothers. The first step of the process involved a non-participant observation, many times a day, of discussions on the group for a year before analysis. Notes were made during this period, which were ethnographically motivated, as the identification and juxtaposition of the two discourses identified previously were clarified. After a year of observations, using NCapture - the web material extraction tool on the qualitative analysis software NVivo, a dataset of all posts made on the group was generated including the group moderator's opening post establishing the parameters of the group. The dataset automatically captured usernames of people who had made posts, the times of posts and all comments made in response to the posts. All posts were read and a purposive sample of posts were selected, the guiding criteria being that posts which were solely information-seeking were not considered. Instead, posts which spoke of experiences, or which provided value-laden assessments of birthing options and choices, and which asked for advice in terms of what action to take were considered in generating the purposive sample. All data was collected non-reactively from a public group with publicly available posts. Non-reactive data collection focuses on data online in the 


\section{INTERPRETATION INTERNET AGE}

public domain, and does not respond to, react or engage with participants online and lets phenomena unfold. A discussion of ethics is imperative here. Whiteman's (2012) account of her work on publicly accessible bulletin boards discusses in detail the ethical considerations behind her decisions to not participate on the forums, to not seek informed consent, and to acknowledge that not seeking informed consent and conducting covert analyses of publicly available data often invites looks of surprise (Whiteman, 2012). The content posted on the forum analysed here are publicly available and do not require the group's membership to view content. The material could therefore be treated as publicly available online material and was treated as such. As posters on Facebook are not anonymous and appear rather with their real names, all names were anonymized before analysis. In order to perform this analysis, each post was first assigned a number (for example - number 14) and each comment on the post was given an alphabetical code (for example - 14A, 14B etc). A decision was made as to what the unit of analysis would be - each post on the group presented itself as a distinct analytical unit ready to use. The units were read, over and again, being assigned codes/labels on NVivo as they were read. This generated a long list of first level labels. These themes were then brought together, read through thoroughly, and grouped into second level themes. It is at this level of analysis that the beginnings of the two discourses emerged as two sides of the same coin, which is what I present in what follows. 


\section{INTERPRETATION INTERNET AGE}

\section{Findings}

Sitting close to the natural birthing movement, a large part of the discourse on the group is about alternative and complementary practices, which lie outside of the periphery of Western medical institutional practices. The sharing of resources on positive affirmations including visual displays such as charts and flashcards reinforcing that a woman's body is her biggest resource in birthing, pictures that are overtly 'positive' in terms of sunrays filtering through the woods, or the wide, open expanse of oceans and skies, and the sharing of wisdom on non-medical practises including aromatherapy, naturopathy and homeopathy feature regularly and strongly in the group. Resource-sharing, camaraderie, distantiation from medical procedures and establishments and a strong sense of supporting each other features in these discussions. This involves a critique of both norms which are considered to be standard in medical institutions (e,g. the induction of labour) and words which are used in common parlance (e.g. pain, contractions, overdue, etc). This critique can be mapped on to the critique of technocratic, medicalised obstetric cultures and serves as the site of camaraderie and solidarity, as in evident in this exchange below -

My husband tells me not to criticise her (a midwife) as she's only trying to help. But I said "hey it's my birth I get to question and criticise anyone I want". Feeling defeat. Ilana

Sadly midwives who tend to fall at the end of the medicalised birth spectrum can see birth plans as a nuisance. Stick to your guns. - Melissa 


\section{INTERPRETATION INTERNET AGE}

Please don't let her deviate you from the path you believe is best for you. - Rihanna There is vitality, camaraderie and real, feminist agency in the support and collegiality extended to mothers as they reject and oppose medical advice and technocratic labour cultures. These have remarkably positive, and even empowering roles to play in the lives of women, who, for instance, like Charlotte, feel helpless and overwhelmed at the thought of labour and birth. There is a strong emphasis here, on women sticking beside each other, in their united rejection of medical procedures and institutions. This theme runs through contemporary scholarship on natural, yet less frequently practiced aspects of mothering (see Miller et al 2007, Lee, 2008 and Faircloth, 2010 writing on certain aspects of infant feeding for instance), whereby rather than parenting becoming about resource sharing, a certain kind of tribalism, exclusion and selective inclusion happens in the way sub-groups form and operate within parenting cultures, generating and drawing from often contrasting discourses and approaches with regard to parenting. In this group, the very terminology adopted in society and in hospitals and birth centres is an object of critique, for the words themselves are interpreted as the gradual dumbing down of women's agency. The group is clear at the outset in that all posts must be about the gentleness and joy of birthing. The word "pain" is forbidden from use in the opening post by the moderator. The group moderator's words state this clearly - "Please use gentle language when you talk on here and refrain (sic) from posting references to 'pain' or 'hurt' would be very helpful'. The rules of telling one's story and of framing one's narrative are set, gently yet firmly, in stone 


\section{INTERPRETATION INTERNET AGE}

here. Scripts that will not conform to the abolishing of specific words, will not be tolerated - a particularly difficult instance of this rule-bound, and almost scripted nature of this discourse is given later in this paper. A simple rule - of avoiding the language of pain or anything difficult or traumatic - enables the production of a group identity which is simultaneously inclusive (of those that conform) and exclusive (of those who do not). John Thompson's exposition of the management of visibility and the struggle for recognition (1995) in everyday life, both processes intrinsically mediated, prove particularly useful to make sense of these processes of inclusion and exclusion - the struggle of narratives, one over the other in these mediated communicative contexts involves and establishes frames of reference which align to a very specific set of maternal subjectivities. A specific kind of birth, and indeed, even, gradations in the desirability of different kinds of natural birth produce birth as essentially a cultural object, creating instead of removing pressures off the shoulders of women, sitting at uncomfortable intersections with the achievements of the natural birthing movement which critically questioned the often problematic medical framing of childbirth as inherently risky and demanding clinical, hospital-based settings by default (see Hausman 2005).

Maternal instinct is valued highly in the group. Mother's instinct must be strong, is inherently right and women are supported emphatically within the community to do their utmost best by their children, by rejecting intervention, refraining from using certain words, and by speaking of positive, joyful experiences. The emphasis on maternal instinct is 


\section{INTERPRETATION INTERNET AGE}

evident below which resonate with Bamberg, Schiffrin, and de Fina's (2007) theorisations of how narrative is made use of to present, produce, maintain and reproduce a coherent story to tell, which operates, in this case, within a particular and specific vision of maternal subjectivity - the joyful mother, enjoying a joyful pregnancy to give birth painlessly.

Your instinct knows best. I have baby 2 due in May and if she shows up again, I might tell that midwife where to stick it! Believe you can xx. - Kiera

Please don't let her (the midwife) make you feel like you are not doing the best for your baby. Your baby is not born yet. Doing what is right for you is what is right for your baby because your health has such an impact on your child's right now. - Clarissa

This emphasis on instinct runs clear and deep throughout and is grasped perfectly by Tyler and Baraitser's reminder of the intensely mediated nature of these discourses centering around the birthing mother as they observe - "if pregnancy was previously imagined as a passive, abject and ordinary physical state to be stoically borne in private, today pregnancy is a disciplinary 'body project' which women are instructed to covet and enjoy." (2013, p7). They grasp perfectly, the pendulum shifts in our mediated frameworks of reference in speaking about birth and birthing bodies. On the one hand, this framework represents the core premise of natural birthing - a critical questioning of white-coated obstetrics, and a return of what is natural. On the other hand, despite the emphasis in this discourse on maternal choice, there are boundaries and limits placed on what maternal behaviour will be supported, what will merely be tolerated and what is most unwelcome. 


\section{INTERPRETATION INTERNET AGE}

The gentle reminder at the outset to not use words such as pain removes the first level of choice for instance. Many women in the course of the fieldwork in the project this work emerges from noted that verbalising pain, including even swearing profusely in labour, gave pain a recognition, a legitimacy, and that helped them in recognising the hard work that labour truly is, and that nothing is quite as extreme perhaps for the body. And yet, in placing strict guidelines on the terminology that is permitted, and that which is not, seems to turn a full circle - from a critique of obstetrics and a return to belief in one's own self (by rejecting the word 'pain') to a discursively visible silencing of women who must conform to the norms of the group and not speak of pain.

One of the key devices used in the group to filter out narratives that do not conform is the device of the "trigger warning". There is bravery and courage ascribed to not feeling or speaking of pain or suffering, and any accounts which do speak of pain, or of women's choices in asking for or accepting pain management are filtered out or accepted with a "trigger warning". For instance a moderator has edited a post that speaks of a difficult birth (if at all this is permitted to remain on the site) - by saying "Warning: May contain triggering material'. The mother who has spoken of difficulty has created a narrative, told a story which has been discursively identified as a "trigger". Triggers, are to be avoided, and therefore, her story has already been mediated to be the other - in relation to whom the rest of the stories are to be read, normalised and accepted. One of the functions of the device of trigger warnings is unwritten blame and guilt - one has posted content which may 


\section{INTERPRETATION INTERNET AGE}

trigger others. Blame and guilt both have key role to play in the intensive mothering discourse (see also Orgad and deBenedictis, 2015) with failing to perform according to these standards resulting in self-blame and guilt (Barnes \& Power, 2012), and blame being placed on 'failing' mothers by the popular press and institutions. While trigger warnings aspire to protect, they become, by default, a policing of women's narratives about birth which allows certain narratives to be opened up and others to be closed down - mediating experiences selectively.

The mother not doing the 'right' thing, or not doing well enough is of course sometimes visible only on probing. Birth stories which are celebrated seem to be the ones that involve no pain relief, a mother who battles through all possible odds in bearing pain whilst not calling it pain, is the mother who shall feel no pain in labour. These stories receive the highest number of replies numerically and are posted in the group straight away. On the odd occasion a mother wishes to share her difficult experiences however, this goes against the ethos of sharing only positivity and joy. An excellent example of the relative status ascribed to birth stories is below, which showed up during my yearlong observation of the group, and has since then been edited including the editing out of certain comments by posters. In the instance below - two occurrences make the semantic status of difficult experiences clear. The gist of a woman's birth story is summarised in one, painful sentence - "I am currently in a rehab to walk because in all the maneuvers to get her out. I have muscle and nerve damage. It's not what I ever expected and I'm just so glad she's alive with 


\section{INTERPRETATION INTERNET AGE}

$u s "$. This story however was unlike other stories - and not allowed to be posted on the group directly. Instead the moderator made the original post using the word "trigger" - but the woman's story itself did not appear on the post. An edited, shortened version of the story was then posted in the comments. Immediately, a set of successive comments were posted in response to this powerful account of a woman's very real struggles - which involved abuse and chastising the woman for sharing negativity. Eventually these comments were taken down. Overall however, this story disappeared into the history of the group drawing only very few comments from posters - a stark contrast to the overwhelming, sometimes tens or over a hundred comments in solidarity and support for 'positive' accounts. This works well with the architecture of social networking sites such as Facebook - the fewer comments something receives, the lower it slips in a news feed, and the lower it slips in a news feed, the longer it takes for a viewer/user to spot the story sliding down fast along a list of other stories generating more comments.

This celebration of instinct, of the good mother doing her absolute best to give birth in a certain way, is framed as a rebuttal and rejection of hyper-medicalisation, but equally involves the establishment of a clear protocol for how to birth 'well', how to be responsible for understanding what qualifies as a 'good' birth and how that is the only route to a healthy baby. This framework of intensive mothering, both an outcome and a component of highly individualized maternal subjectivities is part of a middle-class discourse that is complete with the attendance of often expensive classes, requires rigorous practice and vast amounts 


\section{INTERPRETATION INTERNET AGE}

of self-regulation to avoid thinking of pain in birthing. It takes us close to the dialectical vision of mediation as an understanding of power (see Thompson, 1995) - not just of texts to represent, of information and communication technologies to transmit, but also of women as mothers and individuals to access, interpret and communicate within, against and outside of mediated frameworks of reference. These communication practices, like all communication practices, may work to selectively silence and marginalize, or highlight and bring to relief, the voices and experiences of others. Through the sharing of stories on social media, the circulation of blogs, images, infographics, natural imagery and audio tapes, for each vision of 'good' births, there is created by default an image of birth that's are not good enough. Births that are good births seem to have clearly established parameters and need to be worked towards intensively, methodically and with focus. A non-medical setting, no requirement of pain relieving medication, no interventions, no noise, absolute calm and relaxation paints the picture of the ideal birth - and the ideal birthing woman, who has done her job well - attended classes, practised affirmations, listened to self-hypnosis tapes, practised movements with her birth partner, consciously avoided any exposure to accounts of difficult births, walked away from any woman who seeks to speak of her difficult birth story. On the one hand this is empowering for it is a rejection of fear, doubt, anxiety and an embracing of a natural process - a hard-fought outcome after many decades of silenced women in stirrups surrounded by white coats and intravenous drips. On the other hand, the articulation of this outcome into socially mediated 


\section{INTERPRETATION INTERNET AGE}

codes of good birthing and the responsibilities that come with it establish new norms and new ideals to be aspired for.

One woman on the group epitomises this ideal by speaking of her 'nightmare' birth experience. In this narrative, Cathy says "I was screaming from panic and pain. So loud that nurses were trying to hold me down. I ended up wanting an epidural, and when they attempted to give it to me it was unsuccessful. And then my baby was born in a scary, loud, chaos (sic) environment". She is then re-assured and directed by fellow posters to seek hypnotherapy to free herself of these fears. The epidural is a key protagonist in this nightmare. After the victories of establishing women's choice and agency in rejecting the passivity of women in labour (this victory still un-achieved around the world), a woman who actively chooses or wants any form of medical intervention, even if it is pain relief, in her own words, is poised to fail in her quest for a good birth, as Cathy "ended up" wanting an epidural. The words "ended up" make it clear, that, for Cathy, needing or wanting support to cope with pain is an outcome of defeat, and screaming (a normally comprehensible bodily response to physical pain that we otherwise allow for a variety of life situations) is not an acceptable response in labour. Labour and birth which involves screaming as a response to a natural, yet extreme physical process, or labour and birth which requires the numbing of pain - is a story of nightmares. Indeed, as Ray demonstrates, if one has 'negative' stories (worries, bad experiences) to share and seek support for, the protocol is to not post on the group directly about it, but to warn others seeking avoidance 


\section{INTERPRETATION INTERNET AGE}

of anything negative prior to posting. Ray posts - "Negative post so I will write in comments. But some advice welcomed!' These stories on social media are part of the hermeneutic circle within which childbirth is increasingly mediated. Like all processes and institutions of contemporary societies, birth and labour cannot now be thought of outside of the frameworks of mediation. Responding to others' stories circulating on Facebook, Twitter or parenting forums like BabyCentre or Mumsnet, is one act within a circuit which shapes all future interpretations and understanding (Gadamer, 2002). This circularity, between the present and its past suggests that "our truths are made possible by a shared background of life into which we are initiated, and into which we contribute, through our dialogues and interactions with others" (Martin and Sugarman, 2001, p 197).

Part and parcel of preparing intensively for birth, in a culture of intensive motherhood, is the active work that is demanded of women in preparation for birth, as I have identified above. This also includes the work involved in keeping everything except positivity at bay. This means that women who have had difficult experiences must not be listened to, and only positive stories must be heard. As Natalia requests on her post - "any tips please $x x x$--- PLEASE (capitalized in the original) only positive Notes/ ideas rather than any negative experiences". These narratives underwrite discursive and rhetorical devices which actively close down discussions of births and experiences that have not fallen into the vision of the ideal birth and contribute to the formation of the the maternal individual online as a neo-liberal subject, incorporating very middle-class values of self- 


\section{INTERPRETATION INTERNET AGE}

control, expensive and rigorous preparations and classes. This links the present discussion on birthing and pregnancy online to wider discussions of neo-liberal discourses around good motherhood and good births, and the work involved in mothering and childcare. In keeping with Lee's (2008) empirical work with the self-perception and identity of mothers who have had to or chosen to feed their babies infant formula, research with women who have aspired for, prepared but have not had what would be called ideal births, or completely natural births, may reveal insights about mediated discourses at work in society, in the space that falls between the agentic, critical, rightful revival of women's bodies and voices

against obstetric practice on the one hand, and a pervasive discourse of intensive parenting, in the face of anxiety and perceived risks on the other. Listening to women's voices, on and offline as they speak about these experiences is the only way to begin to unpack that space.

\section{Conclusions}

The role of social media platforms in mediating parenting is now at the heart of studies of parenting and parenting cultures. Despite this, the emotional outcomes of social media use (which might be inclusive/positive/connective or discriminatory/bullying/victimising) in lives of mothers are under-investigated. These outcomes, emergent from the confluence of, as well as feeding into, a whole range of discourses, of course, are far from benign. Evidence exists from within psychology, that discourses of idealized mothering and motherhood have a role to play in the emotional 


\section{INTERPRETATION INTERNET AGE}

well-being of mothers (Rizzo et al; 2013; Stoeber \& Otto, 2006; Hewitt \& Flett, 1991). The takeaway from these studies has usually been that women should not be subscribing to perfectionist ideals about mothering, placing responsibility on women for the uptake of perfectionist ideals, rather than critical investigations of the ways in which these ideals are transmitted and maintained within society, which of course, lies beyond the domain of psychology. Critical-cultural, feminist and broadly sociological interventions in the area provide a way out of this placing of responsibility for women's emotional health on themselves, by offering critiques of the mediated transmission and reproduction of these discourses, when recognizing the clear evidence which exists on the potential impact of the intensive mothering discourse. The clearest area where mothers' emotional health finds public and institutional recognition is in the realm of perinatal mental health, in particular post-natal mental health. While studies exist in obstetrics trying to find linkages between mode of birth and postnatal emotional health, what escapes is an evaluation of the relationships between the ideals and expectations with which women walk into giving birth, itself replete with individualized and hyper-conscious awareness of their own pre-natal roles and preparations (supported also by institutions), and their emotions post-birth depending on their experiences of how birth went in reality. Lee's (2008) and Faircloth's (2013) findings on infant feeding practices does precisely this task, of complicating a terrain which involves women's bodies so centrally - to juxtapose the simultaneity of recognizing women's voice and agency in the face of a medicalized, technocratic discourse, 


\section{INTERPRETATION INTERNET AGE}

when reflecting both in micro and macro terms on the ideals, expectations, disappointment and blame in the earliest days of the mothering experience, where, even before giving birth, standards have been set that are to be aspired for, to be the proper, good, mother. For us to develop a clear understanding of the way parenting, and in this case, specifically, mothering, starts getting mediated from even before parenthood begins, both these lines of critique need to be embedded within each other - the one unwrapping the defiance of technocratic control over the undeniable agency of women as mothers, and the other querying the now decades-long, largely although not solely Western, middle-class discourse of the intensive 'good' mother. Treating these as separate trajectories is less fruitful than putting in more empirical work to be able to link these discourses together, for the intersection and blurring of these produce a rich and meaningful site of analysis. 


\title{
INTERPRETATION INTERNET AGE
}

\author{
References
}

Arendell, T. (2000). Conceiving and investigating motherhood: The decade's scholarship. Journal of Marriage and Family, 62(4), 1192-1207.

Barnes, C., \& Power, M. (2015). Internalising discourses of parenting blame: Voices from the field. Studies in the Maternal, 4(2)

Brady, E., \& Guerin, S. (2010). "Not the romantic, all happy, coochy coo experience": Aqualitative analysis of interactions on an Irish parenting web site. Family Relations, 59(1), 14-27.

Butler, K. (2010). Intensive mothering in british columbia: Understanding the impact of an "Investing-in-children" framework on mothering ideology. International Journal of Canadian Studies, (42), 243.

Chae, J. (2015). “Am I a better mother than you?”. Communication Research, 42(4), 503525.

Chan, A. H. (2008). 'Life in happy land': Using virtual space and doing motherhood in hong kong. Gender, Place \& Culture, 15(2), 169-188. doi:10.1080/09663690701863281

Chen, G. M. (2013). Don't call me that: A techno-feminist critique of the term mommy blogger. Mass Communication and Society, 16(4), 510-532. doi:10.1080/15205436.2012.737888 


\section{INTERPRETATION INTERNET AGE}

Cheresheva, I. (2015). Food for thought: A comparative analysis of online narratives of maternal practices of infant feeding in hungary and bulgaria. Women's Studies International Forum, 53, 147-158.

doi:http://dx.doi.org.ezproxy3.lib.le.ac.uk/10.1016/j.wsif.2014.10.022

Couldry, N. (2004). Theorising media as practice. Social semiotics 14(2). Pp 114-132.

Dahlen, H. G., \& Homer, C. S. E. (2013). 'Motherbirth or childbirth'? A prospective analysis of vaginal birth after caesarean blogs. Midwifery, 29(2), 167. doi:10.1016/j.midw.2011.11.007

De Benedictis, S. (2017) Watching One Born Every Minute: Negotiating the terms of the 'good birth' in R. Mosely, H. Wheatley and H. Wood (eds) Television for Women. Taylor and Francis.

Elliott, S., Powell, R., \& Brenton, J. (2015). Being a good mom. Journal of Family Issues, 36(3), 351-370. doi:10.1177/0192513X13490279

Furedi, F., 2001. Paranoid parenting. London: Penguin.

Faircloth, C. (2010). 'If they want to risk the health and well-being of their child, that's up to them': Long-term breastfeeding, risk and maternal identity. Health, Risk \& Society, 12(4), 357-367.

Fox, B., 2009. When couples become parents: The creation of gender in the transition to parenthood. Toronto: University of Toronto Press. 


\section{INTERPRETATION INTERNET AGE}

Gill, R., \& Orgad, S. (2015). The confidence cult(ure). Australian Feminist Studies, 30(86), 324-344.

Gray, J. (2013). Feeding on the web: Online social support in the breastfeeding context. Communication Research Reports, 30(1), 1-11. doi:10.1080/08824096.2012.746219

Harmsen, I. A., Doorman, G. G., Mollema, L., Ruiter, R. A. C., Kok, G., \& de Melker, H.,E. (2013). Parental information- seeking behaviour in childhood vaccinations. BMC Public Health, 13, 1219-1219. doi:10.1186/1471-2458-13-1219

Hausman, B. (2005). Risky business: Framing childbirth in hospital settings. Journal of Medical Humanities 26(1). Pp 23-38.

Hays, S. (1998). The cultural contradictions of motherhood. Yale University Press

Hewitt, P. L., \& Flett, G. L. (1991). Perfectionism in the self and social contexts: Conception, assessment, and the association with psychopathology. Journal of Personality and Social Psychology, 60, 456-470.

Horeck, T. (2016). The affective labour of One Born Every Minute in its UK and US formats. Critical Studies in Television, 11(2), 164-176.

Johnson, S. A. (2015). ' Intimate mothering publics': Comparing face-to-face support groups and internet use for women seeking information and advice in the transition to first-time motherhood. Culture, Health \& Sexuality, 17(2), 237-251. doi:10.1080/13691058.2014.968807 


\section{INTERPRETATION INTERNET AGE}

Koteyko, N., Hunt, D., \& Gunter, B. (2015). Expectations in the field of the internet and health: An analysis of claims about social networking sites in clinical literature. Sociology of Health \& Illness, 37(3), 468-484

Lee, E. J. (2008). Living with risk in the age of 'intensive motherhood': Maternal identity and infant feeding. Health, Risk \& Society, 10(5), 467-477. doi:10.1080/13698570802383432

Littler, J. (2013). The rise of the " yummy mummy": Popular conservatism and the neoliberal maternal in contemporary british culture. Communication, Culture \& Critique, 6(2), 227-243

Lopez, L. K. (2009). The radical act of ' mommy blogging': Redefining motherhood through the blogosphere doi:10.1177/1461444809105349

Luce, A., Cash, M., Hundley, V., Cheyne, H., Van Teijlingen, E., \& Angell, C. (2016). "Is it realistic?" the portrayal of pregnancy and childbirth in the media. BMC pregnancy and childbirth, 16(1), 40 .

Lupton, D., Pedersen, S., \& Thomas, G. (2016). Parenting and digital media: from the early web to contemporary digital society. Sociology Compass, 10(8), 730-743

Lupton, D., 1999. Risk and the ontology of pregnant embodiment. In: D. Lupton, ed. Risk and sociocultural theory: new directions and perspectives. Cambridge: Cambridge University Press, 59-85. 


\section{INTERPRETATION INTERNET AGE}

Macvarish, J., 2010. The effect of 'risk-thinking' on the contemporary construction of teenage motherhood. Health, Risk \& Society, 12 (4), 313-322.

Madge, C., \& O'Connor, H. (2007). Parenting gone wired: Empowerment of new mothers on the internet? doi:Social and Cultural Geography, 2006, 7(2), pp.199-220; http://hdl.handle.net/2381/1403; http://www.tandfonline.com/doi/abs/10.1080/14649360600600528;

\section{$10.1080 / 14649360600600528$}

McRobbie, A. (2013). Feminism, the family and the new 'mediated' maternalism.(report). New Formations, (80-81), 119.

Miller, T., Bonas, S. and DixonWoods, M. 2007. 'Qualitative research on breastfeeding in the UK: a narrative review and methodological reflection'. Evidence and Policy 3(2): 197-230

O'Connor, H., \& Madge, C. (2012). 'My mum's thirty years out of date' the role of the internet in the transition to motherhood. Scopus, Community Work and Family 7 (3), pp. 351-369; 1366-8803; http://hdl.handle.net/2381/11456; $10.1080 / 1366880042000295754$

Orgad, S., \& De Benedictis, S. (2015). The 'stay-at-home' mother, postfeminism and neoliberalism: Content analysis of UK news coverage. European Journal of Communication 30(4), 418-436. 


\section{INTERPRETATION INTERNET AGE}

Pedersen, S., \& Smithson, J. (2013). Mothers with attitude -- how the mumsnet parenting forum offers space for new forms of femininity to emerge online. Women's Studies International Forum, 38, 97.

Pedersen, S. (2016). The good, the bad and the 'good enough' mother on the UK parenting forum mumsnet. Women's Studies International Forum, 59, 32-38.

Radway, J. (1985). Reading the Romance. University of North Carolina Press.

Riessman, C. K. (2008). Narrative methods for the human sciences. Los Angeles ; London: Sage Publications.

Rizzo, K., Schiffrin, H., \& Liss, M. (2013). Insight into the parenthood paradox: Mental health outcomes of intensive mothering. Journal of Child and Family Studies, 22(5), 614-620.

Rogers, M. (2015). Beyond blogging: How mothers use creative non-fiction techniques in digital environments to dislodge the mask of motherhood. Journal of Family Studies, 21(3), 248-260. doi:10.1080/13229400.2015.1074932

Romagnoli, A., \& Wall, G. (2012). 'I know I'm a good mom': Young, low-income mothers' experiences with risk perception, intensive parenting ideology and parenting education programmes. Health, Risk \& Society, 14(3), 273-289.

Royal College of Midwives. (2014). Maternal mental health. Royal College of Midwives. 


\section{INTERPRETATION INTERNET AGE}

Sears, C. A., \& Godderis, R. (2011). Roar like a tiger on TV? Constructions of women and childbirth in reality TV. Feminist Media Studies, 11(2), 181-195.Silverstone, R. (1999). Why study the media? London: Sage.

Stoeber, J., \& Otto, K. (2006). Positive conceptions of perfectionism: Approaches, evidence, challenges. Personality and Social Psychology Review, 10, 295-319.

Thompson, J. (1995) The Media and Modernity. Cambridge: Polity.

Tyler, I., 2000. 'Reframing Pregnant Embodiment'. In: Ahmed, S et al., eds. Transformations: Thinking through Feminism. London/New York: Routledge, pp. 288302.

Tyler, I., 2001. 'Skin-Tight: Celebrity Pregnancy and Subjectivity'. In: Ahmed, S. and Stacey, J. eds. Thinking through the Skin. London/New York: Routledge, pp. 69-83.

Tyler, I., 2009. 'Birth: An Introduction', Feminist Review, 93, 1-7.

Tyler, I., \& Baraitser, L. (2013) Private view, public birth. Studies in the maternal 5(2).

Wall, G., 2010. Mothers' experiences with intensive parenting and brain development discourse. Women's Studies International Forum, 33 (3), 253-263.

Whiteman, N. (2012). Undoing ethics: Rethinking practice in online research. Boston, MA: Springer US: Boston, MA. doi:10.1007/978-1-4614-1827-6 